\title{
AS REPRESENTAÇÕES SOBRE CULTURA NO E DO ESPORTE PROBLEMATIZADAS NO ENSINO MÉDIO E TÉCNICO AMPLIANDO E APROFUNDANDO OS CONHECIMENTOS
}

\author{
Bruno dos Santos Vilela ${ }^{1}$ \\ Camila Ferreira Ribeiro ${ }^{2}$ \\ Claudson Lincoln Beggiato ${ }^{3}$ \\ Junio Favaro Crema ${ }^{4}$ \\ Marcelo Ferreira Lima ${ }^{5}$ \\ Marcelo Romano Caceres ${ }^{6}$
}

\section{Introdução}

A ETEC ${ }^{7}$ de Esportes Curt Walter Otto Baumgart, por meio do CPS $^{8}$, em seu plano de curso, apresenta Habilitação Profissional Técnica de Nível Médio em Organização Esportiva com o componente curricular denominado "Esporte e Cultura", que tem o objetivo de formar profissionais para o mercado de trabalho de organização esportiva, lazer e recreação, como monitores. Estes poderão auxiliar profissionais de educação física em eventos, clubes ou instituições públicas ou privadas. Esse componente é dividido em Competências, Habilidades e Bases Tecnológicas.

Em resumo, nas competências, solicita-se que cada discente tenha o espaço, tempo e condições de direitos, análise e crítica. Nas habilidades, orienta-se que os discentes possam aprender sobre alguns passos das transformações sociais, legais e culturais que estão inseridas na cultura do e no esporte. E, por fim, as Bases Tecnológicas orientam o docente a ampliar e aprofundar, com cada aluno (a), conteúdos desde a base histórica disponível, passando por leis e marcos, até a discussão sobre a diferença de educação física e esportes entre outros processos culturais. A partir das orientações baseadas no $\mathrm{PPG}^{9}$ e pelo $\mathrm{PC}^{10}$, o $\mathrm{PTD}^{11}$ foi construído com a proposta de dialogar com as questões culturais que envolvem as práticas esportivas.

O curso é formado por módulos que se dividem em um ano e meio. É considerado cada semestre um módulo e dentro do primeiro módulo o componente supracitado faz parte. O relato foi produzido com o $1^{\circ}$ módulo do período da tarde. Este relato se iniciou nas primeiras semanas de fevereiro e estendeu-se até a última semana de março.

O núcleo da questão foi querer saber, discutir, ampliar e aprofundar sobre as questões dos saberes discentes em relação ao que é cultura, relacionando-a com o esporte. Que tipos de representações estavam inseridas nos discentes sobre os temas? Que tipo de influência estavam veladas nos discursos e nos registros? Como uma determinada cultura do esporte pode influenciar no esporte ou vice-versa? Ou seja, de que forma os discentes chegaram à escola e como, a partir das orientações didáticas, o reconhecimento e os saberes se transformaram,

\footnotetext{
${ }^{1}$ E-mail: bruno.turis@gmail.com.

${ }^{2}$ E-mail: camila.ferreira101@etec.sp.gov.br.

${ }^{3}$ E-mail: lincolnbeggiato@gmail.com.

${ }^{4}$ E-mail: junio.crema01@etec.sp.gov.br.

${ }^{5}$ E-mail: folecram2@ hotmail.com.

${ }^{6}$ E-mail: romano.caceres@yahoo.com.br.

${ }^{7}$ Escola Técnica Estadual Etec de Esportes Curt Walter Otto Baumgart do Governo do Estado de São Paulo.

${ }^{8}$ Centro Estadual de Educação Tecnológica Paula Souza.

${ }^{9}$ Plano Plurianual de Gestão.

${ }^{10}$ Plano de Curso.

${ }^{11}$ Plano de Trabalho Docente.
} 
possibilitando, assim, uma justiça curricular, diminuição do "daltonismo" cultural e ancoragem social dos conhecimentos.

\section{Revisão de literatura}

As bibliografias que pautam este trabalho, na questão da análise para o relato, estão na perspectiva culturalmente orientada, com influência do multiculturalismo crítico que está incorporado no Currículo Cultural da Educação Física.

Sobre os conceitos acerca das representações sobre o esporte foi utilizado o texto de Valdir Barbante (2006) e de Marcos Garcia Neira (2014) e, no conceito de cultura, com Neira e Nunes (2008). Já para a questão de gênero, foram base Aguiar et. al. (2016), Altmann (2014), Goellner (2006), Jaeger (2007) e Louro (1997).

\section{Materiais e métodos}

Para início dos trabalhos, na primeira semana de aula, não houve nenhuma intervenção para o aprendizado específico. Nesta, foram apresentados todos os documentos que orientam as práticas discentes e docentes na instituição escolar. Além disso, outras condições foram expostas, como o processo avaliativo, datas e possíveis eventos e apresentações.

É importante salientar que os registros são produzidos em todas as aulas, ou seja, as problematizações são realizadas a partir da participação de todos no grupo e registradas em folha ou na lousa conforme as imagens.

Na segunda semana, iniciaram-se os trabalhos específicos. Aqui, num primeiro momento, as discussões foram sobre o que representava o esporte para cada um. Formaram-se, então, grupos para que cada integrante se posicionasse de forma democrática e, posteriormente, apresentasse uma discussão.

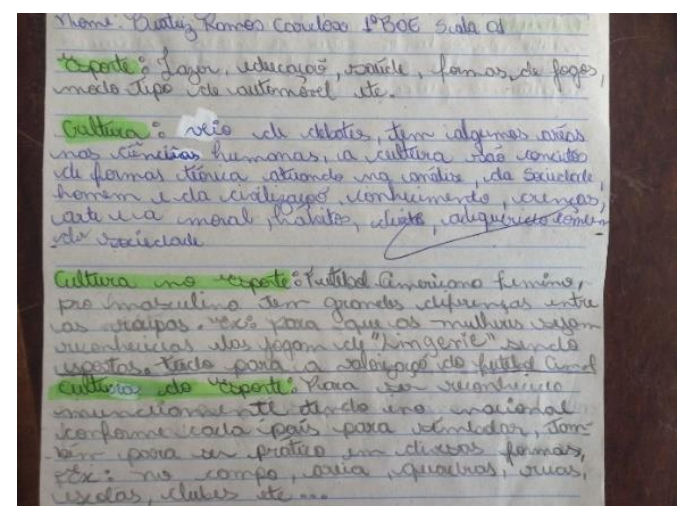

Imagem 1. Registro das representações sobre Esporte e Cultura - Fonte: Elaboração própria

Na semana seguinte, foram apresentados os textos de Barbanti (2006) e Neira (2014) para leitura e discussão em grupo. Cada grupo levou o texto para leitura nos locais mais oportunos, e, em seguida, voltaram para apresentar suas representações sobre os textos e comparar com a aula anterior.

Em outra aula foi realizado o mesmo processo; porém, com a representação sobre cultura. Cada grupo se posicionou e debateram entre eles. E, na aula seguinte, os discentes receberam textos sobre cultura, NEIRA (2008), para leitura, interpretação e debate.

Após, e, conforme o Plano de Curso, o esporte futebol foi inserido para o processo de aprendizado no componente curricular de Esporte e Cultura. Com isso, foi realizado o processo 
de mapeamento dos saberes individuais/grupo. Houve debates entre os grupos a respeito das representações culturais sobre o futebol feminino.

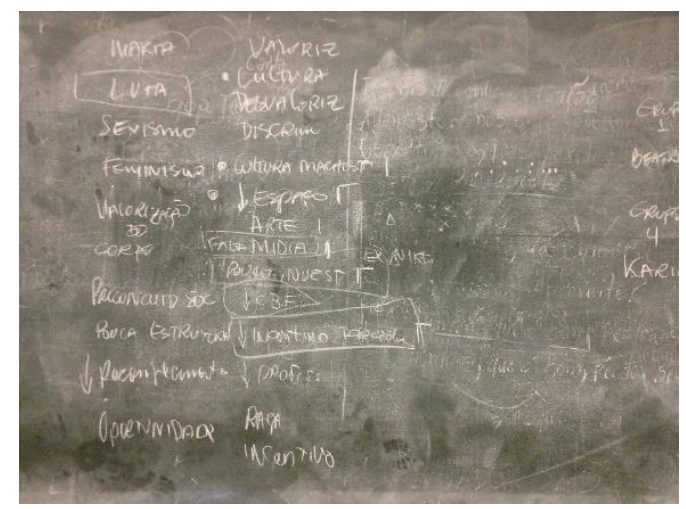

Imagem 2. Registro das representações sobre o futebol feminino - Fonte: elaboração própria

Os grupos posicionaram-se e debateram sobre o tema a partir das representações registradas em folhas e na lousa conforme imagem 2.

$\mathrm{Na}$ aula seguinte, foram solicitados novos registros sobre os temas abordados. De certa forma, alguns alunos retomaram as representações iniciais. Outros já registraram sobre suas ressignificações e alguns não participaram e outros/as, no debate, disseram não se lembrar dos textos dos autores debatidos em sala de aula.

Com isso, refez-se o caminho, "nova rota", com debates em sala sobre os temas de esporte e cultura, e a análise de um vídeo contendo em seu conteúdo os temas referidos.

\section{Resultados}

Na primeira intervenção sobre o que é esporte, alguns discentes relacionaram o esporte a brincadeiras como a queimada e mencionaram atividades diversas como patins no parque. Outros deram exemplos de esportes e citaram alguns nomes de atletas.

Também houve a "defesa" de um esporte em específico. Um grupo falou sobre o futebol e sua estrutura hegemônica em relação ao voleibol. Outro grupo se manifestou dizendo: "o futebol é o melhor esporte no Brasil". O grupo que defendeu o esporte voleibol teve a garantia de manifestação e também se posicionou. Depois vieram outras discussões sobre outras modalidades esportivas.

Sobre o conceito de cultura produziram da mesma forma e também levaram em consideração vivências familiares como causa da representação, ou seja, deram exemplos de discurso dos familiares sobre o tema. Em seguida, foi realizada a leitura do texto de Neira e Nunes (2008) que trata do que é cultura, em que quatro dos sete grupos se posicionaram, dizendo que suas primeiras representações estavam de acordo com as leituras dos textos. "Os textos estavam apenas mais formais", "fala de um grupo".

Sobre a representação do esporte futebol, sete dos dez grupos assinalaram apenas pontos positivos em torno da prática e três grupos sinalizaram aspectos positivos e negativos. Alguns alunos não se lembraram dos conteúdos dos textos sobre o conceito de esporte e de cultura discutidos em sala de aula. Com isso, uma nova rota foi construída e, a partir da análise do vídeo e da retomada das discussões, eles puderam rever e rediscutir o conteúdo em questão.

Neste momento, a partir das reorientações didáticas, a retomada se produziu por meio das releituras. Estas foram apresentadas de diversas formas, como o vídeo e a manifestação dos discentes que se posicionaram, quando relembraram o texto oralmente ou consultando seus registros. 


\section{Discussão}

Num primeiro momento, sobre os saberes iniciais e com os registros, pode-se afirmar que, para o tema "esporte", alguns discentes que tinham suas representações de que qualquer atividade física se remetia ao conceito de esporte se ressignificaram. Para os demais, pôde-se perceber que seus conhecimentos se ampliaram pelo fato de terem a oportunidade de leitura, interpretação, acesso e debate sobre os conceitos. Além disso, a possibilidade de ter a "voz" compartilhada com as demais pessoas fortalece sua participação no processo de aprendizagem e reconhecimento do Outro $^{12}$ e suas representações.

No que se refere às representações sobre cultura, foi interessante a proximidade de saberes em relação ao texto lido e interpretado. Isso significa que certos acessos aos conhecimentos e de interpretação sobre o tema "cultura" são significativos no processo de aprendizagem.

E, em relação ao esporte futebol, alguns apresentaram a visão positivista da prática, enquanto outros demonstram, além das questões positivas, aspectos considerados negativos.

\section{Conclusão}

Pode-se identificar que abrir espaço de direito para se manifestar e justificar sua posição como autor de desejos e interpretações foi significativo para todos. Em relatos, orais ou escritos, os discentes comunicaram isso. "Poder falar o que penso é muito da hora". "Poder ouvir e ver o outro me trouxe a possibilidade de reconhecer que existe outros pensamentos e posicionamentos". "Eu acho muito loco o debate. Poderia ter mais". "Mostrar o que penso para outras pessoas me deixa nervosa, mas foi muito legal. Acho legal assim”. Fala de alguns discentes.

Outra identificação foi a própria forma de orientação didática na aula. Percebeu-se que o imediatismo está presente em alguns alunos e alunas neste formato. As discussões, no dia dos registros das representações e leituras posteriores, foram bem amplas e profundas; porém, duas aulas depois, tais debates estavam esgotados para alguns discentes. Com isso, recorreu-se a uma reapresentação com novos debates e discussões em sala, "novas rotas" o que, naquele momento, foi significativo para todos.

Em suma, o trabalho sobre esporte; cultura; cultura no e do esporte, no componente de esporte e cultura pode ampliar e aprofundar os conhecimentos de todas as pessoas envolvidas, alunos (as) e professor. Ampliou no sentido de obter mais informações sobre as funções desenvolvidas no processo de aprendizagem e aprofundou-se pelas análises, debates e discussões sobre o universo da aula e seus objetivos. Com isso, alunas e alunos se posicionaram, tiveram seu direito de voz garantido, puderam reconhecer o Outro como detentor de representações diferentes, e, puderam, assim, ressignificar suas posições em relação às diferenças. De certa forma, também, auxiliaram na reavaliação e recomposição das orientações didáticas na aula, podendo, portanto, reestabelecer novas formas para novos ensinos e aprendizados.

\section{Referências}

ALTMANN, Helena. Educação Física Escolar: relação de gênero em jogo. São Paulo, SP. Cortez, 2015.

AGUIAR, A. A. D. et al. Relações de Gênero na prática do futebol. In: NEIRA, M. G.;

\footnotetext{
${ }^{12} \mathrm{O}$ Outro aqui com letra maiúscula se refere às diferenças em todos os aspectos.
} 
NUNES, M. L. F. (Org.) Educação Física Cultural: escritas sobre a prática. 1. ed. Curitiba, PR: CRV, 2016, p. 165-180.

BARBATI, Valdir. $O$ que é esporte? Disponível em: <https://periodicos.ufpel.edu.br/ojs2/index.php/RBAFS/article/view/833/840>. Acesso em: 6 fev. 2017.

GOELLNER, Silvana Vilodre. As práticas corporais e esportivas e a produção de corpos generificados. In: SOARES, G. F.; da SILVA, M. R. S.; RIBEIRO, P. R. C. (Org.) Corpo, Gênero e Sexualidade: tematizando práticas educativas e culturais. Rio Grande: FURG, 2006, p. 37-40.

JAEGER, Angelita Alice. Quando o músculo entra em cena: fragmentos históricos da potencialização muscular feminina. In: GOELLNER, S. V.; JAEGER, A. A. (Org.). Garimpando Memórias: esporte, educação física, lazer e dança. Porto Alegre, RS. UFRGS, 2007, p. 133-146.

LOURO, Guacira Lopes. Gênero, Sexualidade e Educação: uma perspectiva pós-estruturalista. Petrópolis: Vozes, 1997.

NEIRA, M. G.; NUNES, M. L. F. Pedagogia da Cultura Corporal: críticas e alternativas. 2. ed. São Paulo: Phorte, 2008, p. 19-61.

Práticas Corporais: brincadeiras, danças, lutas, esportes e ginásticas. São Paulo: Melhoramentos, 2014, p. 124-139.

Significados do Esporte. Disponível em: <https://www.youtube.com/watch?v=kshbtPBII3Q>. Acesso em: 31 mar. 2017. 